\title{
AVALIAÇÃO DA SENSITIZAÇÃO EM AÇOS INOXIDÁVEIS FERRÍTICOS ESTABILIZADOS E NÃO ESTABILIZADOS USANDO-SE A TÉCNICA REATIVAÇÃO ELETROQUÍMICA POTENCIOCINÉTICA EM MEIO SULFÚRICO
}

\begin{abstract}
Adriana Diniz Barbosa 1
Fernanda Martins Sousa ${ }^{2}$

Jose Antonio Nunes Carvalho 3

Carlos Roberto Araújo 4

Luiz Cláudio Cândido 5
\end{abstract}

Resumo

Avaliou-se o estado de sensitização de aços inoxidáveis ferríticos AISI: 430; 439; 444, e um do tipo modificado (P430). Variaram-se as condições de temperatura e tempo de permanência em um forno, e mediram-se os resultados empregando-se as técnicas de ensaios de corrosão intergranular, Prática W (Norma ASTM A 763 - 93), e técnicas não destrutivas, quantitativas, de reativação eletroquímica potenciocinética (polarização cíclica com duplo loop). A partir de temperatura de $900^{\circ} \mathrm{C}$, empregaram-se tempos de 10 e 20 minutos, com resfriamentos em forno, ao ar, em água, óleo e nitrogênio líquido. Para caracterizar qualitativamente a precipitação de carbonetos, utilizou-se microscopia ótica. Notou-se que em condições de resfriamentos mais lentos ocorreu maior grau de sensitização para os aços AISI 430 e P430, nos outros aços não detectou-se precipitação de carbonetos em contornos de grão.

Palavras-chave: Aço inoxidável ferrítico; Sensitização; Técnica eletroquímica.

\section{EVALUATION OF SENSITIZATION OF FERRITICS STAINLESS STEELS STABILIZED AND NOT STABILIZED USING ELECTROCHEMICAL TECHNIQUES IN SULPHURIC ENVIRONMENT}

\begin{abstract}
The degree of sensitization in ferritics stainless steels AISI: 430; 439; 444 and an altered type, P430, was evaluated by electrochemical reactivation method DL-EPR (cyclical polarization with double loop) and by techniques of intergranular corrosion, W Practice (ASTM 763 - 93). The samples of stainless steel were treated at $900^{\circ} \mathrm{C}$ and $950^{\circ} \mathrm{C}$ (in times of 10 and 20 minutes) and cooled at different rates in the furnace, to air, in water, in oil and liquid nitrogen. The results of the DL-EPR test show that the sensitization degree varies in function of cooling. The steel P430 has apresented bigger sensitization degree during the slow cooling.
\end{abstract}

Key words: Ferritic stainless steel; Sensitization; Electrochemical technique.

\section{INTRODUÇÃO}

Os aços inoxidáveis convencionais podem ser suscetíveis à corrosão intergranular após determinados tratamentos térmicos.(1) Os aços inoxidáveis ferríticos não estabilizados apresentam um obstáculo considerável na sua utilização em decorrência da suscetibilidade à corrosão intergranular.(2) Através de técnicas de EPR (Reativação Eletroquímica Potenciocinética), o grau de sensitização de aços inoxidáveis ferríticos, estabilizados e não estabilizados, foram avaliados nesse trabalho. Este método já vem sendo apli- cado com sucesso para aços inoxidáveis austeníticos e recentemente para os martensíticos, mas para os ferríticos, existem poucos dados sobre sua aplicação.(3) A necessidade de um estudo aprofundado sobre a utilização de materiais sensitizados, fenômeno que pode causar precipitação de carbonetos de cromo resultando em ataque intergranular, deu-se devido à não aceitação dessa utilização em determinados processos quando se tratando de aços inoxidáveis ferríticos.

\footnotetext{
1 Eng. Controle e Automação; Mestra em Engenharia de Materiais - REDEMAT/UFOP; adrianadinizbarbosa@gmail.com

2 Aluna de Eng. Metalúrgica - DEMET/EscoladeMinas/UFOP; fernanda@metalurgia.em.ufop.br

3 Eng. Metalurgista; M.Sc. - ACESITA S.A.; jancarvalho@acesita.com.br

4 Eng. Metalurgista; M.Sc.; carlosroberto_araujo@yahoo.com.br

5 Membro da ABM; Eng. Metal; M.Sc.; D.Sc.; Prof. Adjunto do Dep. Eng. Metal. e de Materiais/Escola de Minas/UFOP-REDEMAT; candido@em.ufop.br
} 
Tabela 1. Composição química dos aços (\% peso).

\begin{tabular}{ccccccccccc}
\hline AÇOS & C & Cr & Mo & Nb & Ti & Ni & Mn & Si & P & $\mathbf{N}_{2}(\mathbf{p p m})$ \\
\hline P430 $\left(^{*}\right)$ & 0,024 & 16,160 & 0,019 & 0,026 & 0,106 & 0,170 & 0,260 & 0,350 & 0,028 & 231 \\
AISI 444 & 0,009 & 17,680 & 1,810 & 0,170 & 0,140 & 0,200 & 0,140 & 0,360 & 0,027 & 118 \\
AISI 430 & 0,049 & 16,160 & 0,016 & 0,016 & 0,010 & 0,200 & 0,400 & 0,310 & 0,028 & 482 \\
AISI 439 & 0,010 & 17,230 & 0,020 & 0,190 & 0,180 & 0,180 & 0,170 & 0,440 & 0,025 & 118 \\
\hline
\end{tabular}

$\left(^{\star}\right)$ - Aço AISI 430 com composição química modificada.

\section{MATERIAIS E MÉTODOS}

As amostras para análises e ensaios foram retiradas a partir de chapas de aços inoxidáveis ferríticos, no estado de entrega. A Tabela 1 apresenta a composição química dos materiais.

O material foi recebido na forma de chapas com espessuras, aproximadas, de $1 \mathrm{~mm}$. Foram cortadas amostras quadradas com aproximadamente $80 \mathrm{~mm}$ de lado e amostras circulares com diâmetro de $10 \mathrm{~mm}$. Foi feito tratamento térmico, em forno do tipo mufla, a $900^{\circ} \mathrm{C}$ no aço P430 e AISI 430 , e a $950^{\circ} \mathrm{C}$ no aço AISI 444 e AISI 439, durante 10 e 20 minutos, com resfriamentos em forno, ar, óleo, água e nitrogênio líquido.

Após os tratamentos térmicos, as amostras foram lixadas até lixa com granulometria 600 e desengraxadas. Os ensaios eletroquímicos foram feitos em um potenciostato/galvanostato PAR, modelo 273A. O método DL-EPR foi realizado utilizando-se aproximadamente $300 \mathrm{ml}$ de solução aquosa aerada, contendo 0,5M $\mathrm{H}_{2} \mathrm{SO}_{4}$, preparada a partir de reagente padrão analítico e água destilada, à temperatura ambiente. Foi utilizada uma célula eletroquímica plana, um eletrodo de referência de calomelano saturado (ECS) e um contra-eletrodo de platina. As amostras foram lixadas e desengraxadas imediatamente antes de serem imersas no eletrólito, onde permaneceram por 5 minutos estabilizando o potencial de corrosão. O material foi polarizado anodicamente a partir do potencial de corrosão $\left(E_{\text {cor }}\right.$ ) até $300 \mathrm{mV}_{\text {ecs }}$ (zona de passivação). Posteriormente, fez-se a reversão até o potencial de corrosão do sistema aço/meio. Tanto na ativação quanto na reversão a velocidade de varredura empregada foi de 1,67 $\mathrm{mV} / \mathrm{s}$. A área ensaiada das amostras foi de $1 \mathrm{~cm}^{2}$. Ao término dos ensaios foram obtidos os valores de densidade de corrente máxima $\mathrm{l}_{\mathrm{a}}$ (processo de ativação), e a densidade de corrente máxima $I_{r}$ (processo de reversão). O grau de sensitização (GS) foi obtido através do quociente entre os dois máximos de densidade de corrente, $\mathrm{I}_{\mathrm{r}} \mathrm{l}_{\mathrm{a}}$. Essa técnica é abordada em maior profundidade por Wolynec.(4)
Os ensaios em ácido oxálico foram realizados segundo os procedimentos da Prática W (Norma ASTM A763-93).(5) As amostras foram lixadas até lixa com granulometria 600 e atacadas eletroliticamente em solução aquosa contendo $10 \% \mathrm{H}_{2} \mathrm{C}_{2} \mathrm{O}_{4} \cdot 2 \mathrm{H}_{2} \mathrm{O}$ (ácido oxálico), a uma densidade de corrente de $1 \mathrm{~A} / \mathrm{cm}^{2}$, durante aproximadamente 90s. Após ataque com ácido oxálico, foi realizada análise microestrutural com microscopia ótica.

\section{RESULTADOS E DISCUSSÃO}

As Figuras 1 e 2 mostram fotomicrografias de corpos-deprova (CPs) dos aços P430 e AISI 430 submetidos a tratamento térmico a $900^{\circ} \mathrm{C}$ durante 10 minutos, após emprego da Prática W. As amostras resfriadas ao ar apresentaram resultados com ataques diferentes, onde alguns contornos de grão apresentaram maior incidência de precipitados em toda sua extensão, alguns em menor proporção e outros uma quantidade mínima.

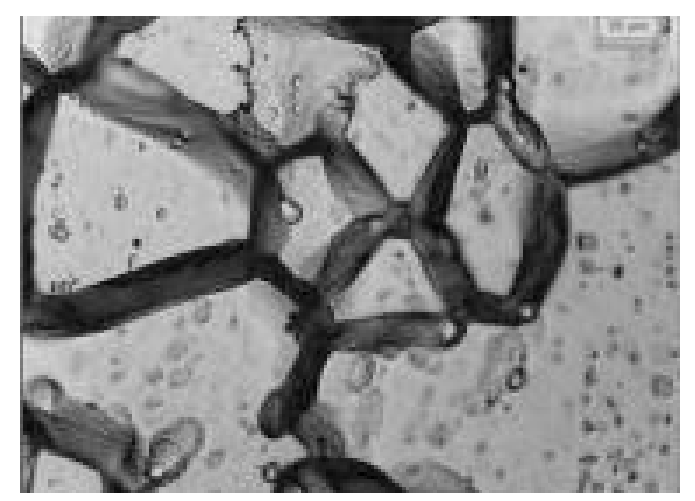

Figura 1. Microestrutura de um aço $\mathrm{P} 430$; aquecido a $900^{\circ} \mathrm{C}-10$ minutos; resfriado ao ar; após Prática $\mathrm{W} ; 500 \mathrm{X}$.

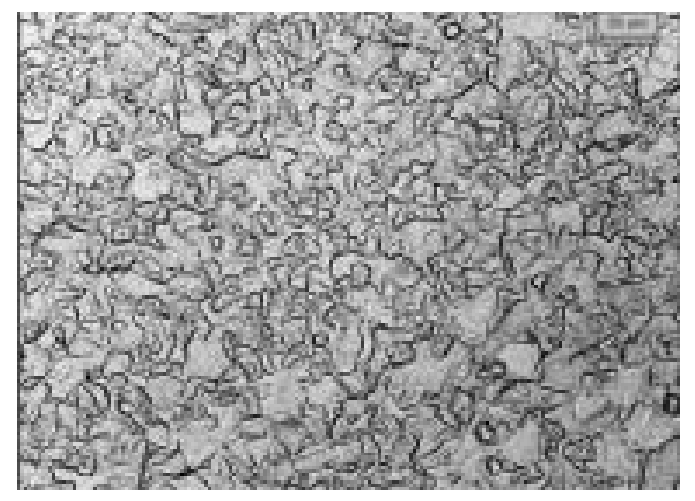

Figura 2. Microestrutura de um aço AISI 430 ; aquecido a $900^{\circ} \mathrm{C}-10$ minutos; resfriado ao ar; após Prática W; 500X. 
Nota-se na Figura 1, a existência de valas devido ao ataque em decorrência da precipitação de carbonetos de cromo; da mesma forma, foi constatado para o resfriamento em água. Este comportamento também foi observado por Giraldo, Magnabosco e Falleiros (6) que utilizaram um aço inoxidável ferrítico UNS S43000, tratado termicamente a $1.200^{\circ} \mathrm{C}$, durante 20 minutos. Observaram que o resfriamento em água revelou grãos de ferrita recristalizados, com contornos de grão atacados em diferentes intensidades na mesma amostra; alguns contornos apresentaram valas profundas, outras mais rasas e ainda algumas com apenas um leve ataque. Outra característica importante, é que não encontraram grão algum totalmente envolvido por valas. Eles notaram que o resfriamento em água produziu microestruturas totalmente ferríticas.

Giraldo, Magnabosco e Falleiros(6) observaram também que, para o resfriamento ao forno, foram encontradas valas em contornos de grão da ferrita e em contornos ferrita/austenita, o que indicava a ocorrência de precipitação de carbonetos de cromo. Além disso, no caso do resfriamento ao forno, encontraram grãos totalmente envolvidos por valas, o que justificou o encaminhamento das amostras para outras Práticas ( $X, Y$ ou $Z)$, visto que, as já ensaiadas pela Prática $W$ não seriam aceitas pelos critérios da Norma ASTM A763-93.(5)

Para o caso de resfriamento em água, notou-se um ataque intermediário entre os resfriamentos ao ar e ao forno no aço P430. Já o aço AISI 430, para ambos resfriamentos (ar e água), apresentou um ataque intenso, o que dificultou uma análise mais detalhada da microestrutura. No caso dos aços AISI 439 e 444 não foi observado ataque intergranular.

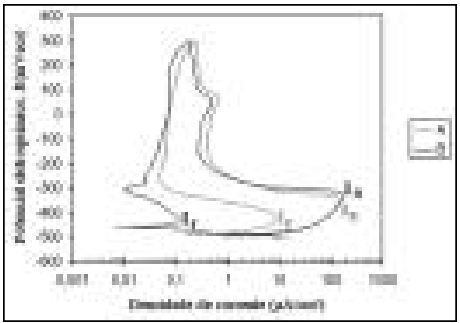

(a)

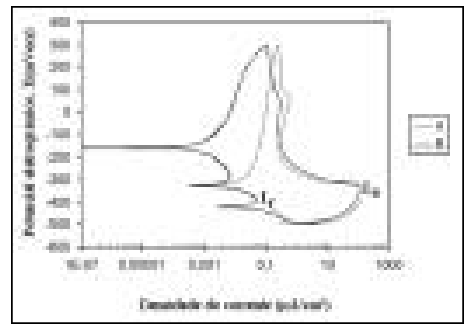

(b)
Figura 3. Curvas de polarização cíclica obtidas pelo método DL-EPR. Sistema: aço P430 / 0,5 $\mathrm{M} \mathrm{H}_{2} \mathrm{SO}_{4}$; após aquecimento a $900^{\circ} \mathrm{C}$ durante: "A" 10 minutos; "B" 20 minutos; $1,67 \mathrm{mV} / \mathrm{s}$; temperatura ambiente; (a) resfriamento ao forno; (b) resfriamento em água.

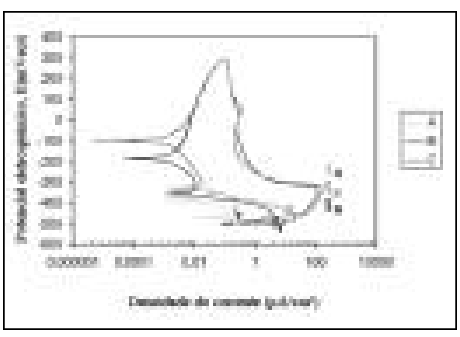

(a)

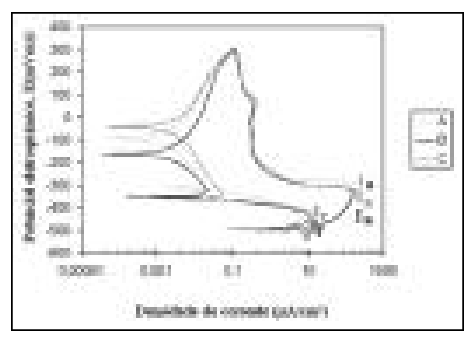

(b)
Figura 4. Curvas de polarização cíclica obtidas pelo método - DL-EPR. Sistema: aço AISI 430/0,5M $\mathrm{H}_{2} \mathrm{SO}_{4}$; (a) resfriamento em "A" Água, "B" Óleo e "C" Nitrogênio líquido após aquecimento a $900^{\circ} \mathrm{C}$ durante 10 minutos; (b) resfriamento em "A" Água, "B" Nitrogênio líquido e "C" Forno; após aquecimento a $900^{\circ} \mathrm{C}$ durante 20 minutos. $1,67 \mathrm{mV} / \mathrm{s}$; temperatura ambiente.
Observou-se que as amostras, após a Prática $\mathrm{W}$, apresentaram intensidades de ataque diferenciadas, o que revela a presença de diferentes quantidades de carbonetos de cromo precipitados em contornos de grão, porém, pouco se pode concluir sobre o grau de sensitização das amostras. Para isso, foram realizados ensaios de reativação eletroquímica potenciocinética do tipo Duplo Loop (método DL-EPR), dos quais, alguns resultados estão apresentados nas Figuras 3 a 5.

No entanto, em alguns casos, observouse a ocorrência de um segundo máximo de densidade de corrente, que, segundo Magri,(7) seria outro parâmetro sugerido na literatura para se avaliar o grau de sensitização de aços inoxidáveis ferríticos. Para Pires e Falleiros,(8) este segundo máximo ocorre em amostras que possuem regiões empobrecidas em cromo, e devido a esse fato, não se passivam, ficando suscetíveis à corrosão. Esse comportamento, provavelmente, ocorreu em função da instabilidade do filme passivo. Giraldo e Falleiros(9) também observaram esse comportamento, porém empregaram aquecimento a $600^{\circ} \mathrm{C}$. As curvas para o aço do tipo AISI 444 e AISI 439, em duas condições extremas de resfriamento, forno e nitrogênio líquido, mostraram que não ocorreu o aparecimento do segundo "joelho" na curva durante a reversão, portanto, ausência de $I_{r}$. Pode-se considerar que praticamente não houve sensitização para ambos os aços. Esse fato pôde ser comprovado com emprego da Prática W (ataque com ácido oxálico). A Tabela 2 mostra valores do grau de sensitização para os sistemas analisados.

A Figura 3 (a) mostra que ocorreu sensitização no aço P430, resfriado ao forno, devido a existência da densidade de corrente de reativação, $I_{r}$. Comportamento semelhante também foi observado em condições de resfriamento ao ar e em óleo. O maior grau de sensitização pôde ser constatado no resfriamento ao forno (10 minutos) e ao ar (20 minutos).

Para o tempo de tratamento térmico de 10 minutos e resfriamento ao forno (Figura 4), o comportamento do aço AISI 430 foi semelhante em sensitização para os resfriamentos ao ar, óleo, água e nitrogênio líquido. Também foi observado esse comportamento após tratamento térmico durante o tempo de 20 minutos para todos resfriamentos do aço AISI 430 . É importante ressaltar que o maior grau de sensitização foi observado no resfriamento em nitrogênio líquido, o que reforça a instabilidade ocorrida durante esse ensaio. 
Tabela 2. Graus de sensitização dos aços empregando-se o método DL-EPR; tempos de permanência no forno: (a) 10 minutos; (b) 20 minutos.

\begin{tabular}{|c|c|c|c|c|c|c|c|}
\hline \multicolumn{2}{|c|}{ Tratamento térmico } & \multirow{3}{*}{ Aços } & \multicolumn{5}{|c|}{ Grau de sensitização $\left(I_{r} / I_{a}\right)$} \\
\hline \multirow{2}{*}{ Tempo } & \multirow{2}{*}{ Temperatura } & & \multirow[b]{2}{*}{ FORNO } & \multirow{2}{*}{\multicolumn{2}{|c|}{$\begin{array}{c}\text { Resfriamentos } \\
\text { ÓLEO }\end{array}$}} & \multirow[b]{2}{*}{ ÁGUA } & \multirow[b]{2}{*}{$\mathrm{N}_{2}$} \\
\hline & & & & & & & \\
\hline $10 \mathrm{~min}$. & $900^{\circ} \mathrm{C}$ & P430 & $61,17 \times 10^{-3}$ & $3,87 \times 10^{-3}$ & $0,26 \times 10^{-3}$ & --- & --- \\
\hline & $950^{\circ} \mathrm{C}$ & AISI 444 & --- & --- & --- & --- & --- \\
\hline & $900^{\circ} \mathrm{C}$ & AISI 430 & $15,83 \times 10^{-3}$ & $43,86 \times 10^{-3}$ & $32,18 \times 10^{-3}$ & $1,09 \times 10^{-3}$ & $66,79 \times 10^{-3}$ \\
\hline & $950^{\circ} \mathrm{C}$ & AISI 439 & --- & --- & --- & --- & --- \\
\hline
\end{tabular}

(a)

\begin{tabular}{|c|c|c|c|c|c|c|c|}
\hline \multirow{2}{*}{\multicolumn{2}{|c|}{ Tratamento térmico }} & \multirow{3}{*}{ Aços } & \multicolumn{5}{|c|}{ Grau de sensitização $\left(I_{r} / I_{a}\right)$} \\
\hline & & & \multirow[b]{2}{*}{ FORNO } & \multirow{2}{*}{\multicolumn{2}{|c|}{$\begin{array}{c}\text { Resfriamentos } \\
\text { ÓLEO }\end{array}$}} & \multirow[b]{2}{*}{ ÁGUA } & \multirow[b]{2}{*}{$\mathrm{N}_{2}$} \\
\hline Tempo & Temperatura & & & & & & \\
\hline \multirow[t]{4}{*}{20 min. } & $900^{\circ} \mathrm{C}$ & $\mathrm{P} 430$ & $0,68 \times 10^{-3}$ & $3,28 \times 10^{-3}$ & $2,32 \times 10^{-3}$ & $0,41 \times 10^{-3}$ & $2,12 \times 10^{-3}$ \\
\hline & $950^{\circ} \mathrm{C}$ & AISI 444 & -- & -- & -- & -- & -- \\
\hline & $900^{\circ} \mathrm{C}$ & AISI 430 & $87,89 \times 10^{-3}$ & $73,07 \times 10^{-3}$ & $85,10 \times 10^{-3}$ & $30,94 \times 10^{-3}$ & $66,53 \times 10^{-3}$ \\
\hline & $950^{\circ} \mathrm{C}$ & AISI 439 & -- & -- & -- & --- & --- \\
\hline
\end{tabular}

(b)

Pode-se observar que 0 aço P430 apresentou sensitização em quase todas as condições de resfriamento e tempo, principalmente quanto ao resfriamento ao forno. Destacase 0 alto grau de sensitização $\left(61,17 \times 10^{-3}\right)$ para o resfriamento em forno, quando o aço P430 foi aquecido durante 10 minutos. No entanto, para a mesma condição, porém em 20 minutos obtevese um valor de GS menor $\left(0,68 \times 10^{-3}\right)$, inclusive inferior a outros meios. Isso, provavelmente ocorreu devido a uma recuperação da resistência à corrosão intergranular do aço. Já o aço AISI 430 , apresentou maior grau de sensitização em praticamente todas as condições de resfriamento a que foi submetido após 20 minutos de tratamento térmico e valores, em grande parte, menores para 10 minutos.

Pode-se observar na Figura 5, curvas de aços do tipo AISI 444 e AISI 439, após tratamento térmico a $950^{\circ} \mathrm{C}$, em duas condições extremas de resfriamento, forno e nitrogênio líquido não ocorreu o aparecimento do segundo "joelho" na curva durante a reversão, portanto, ausência de $I_{r}$. Assim, pode-se considerar que praticamente não houve sensitização para ambos os aços. Esse fato pôde ser comprovado com emprego da Prática W (ataque com ácido oxálico). Este comportamento ocorreu em todos os resfriamentos (forno, ar, óleo, água e nitrogênio líquido) nos aços do tipo AISI 444 e AISI 439 durante os tempos de 10 e 20 minutos. Portanto, estes aços não sofreram o fenômeno de sensitização.

Giraldo e Falleiros(10) a partir de um aço inoxidável ferrítico do tipo UNS S43000 solubilizado a $1.200^{\circ} \mathrm{C}$, resfriado em água, e tratado isotermicamente a temperaturas entre $500^{\circ} \mathrm{C}$ e $700^{\circ} \mathrm{C}$ em tempos variados, observaram que a condição solubilizada apresentou um valor de grau de sensitização, $G S=I_{r} / I_{a}=0,0025 \pm 0,0026$. Em temperaturas de 500,550,600, 650 e $700^{\circ} \mathrm{C}$ houve grande variação do GS em função do tempo e temperatura de tratamento térmico. No entanto, a $700^{\circ} \mathrm{C}$ ocorreu recuperação do aço, indicando baixos valores de GS. No presente trabalho, obtiveramse os valores de GS, para o aço $\mathrm{P} 430$, com tratamento a $900^{\circ} \mathrm{C}$, durante 10 minutos, resfriado ao forno, de 0,0612 e, de 0,016 para o aço AISI 430.

$\mathrm{Na}$ avaliação do GS através do resfriamento em nitrogênio líquido foi possível constatar que os aços P430 e AISI 430 apresentaram suscetibilidade a sensitização, embora exista dificuldade no sistema de resfriamento devido à atmosfera gasosa presente.

Lopes(11) e Lopes e Cândido(12) empregaram as mesmas técnicas, porém, em um aço austeníticos, AISI 304 (Norma ASTM A262-93, Prática A),(13) também observaram uma maior sensibilidade do método DL-EPR para avaliar o grau de sensitização do material.

Giraldo e Falleiros(14) utilizando o aço UNS $\$ 43000$ correlacionaram o ensaio de imersão (Prática X - Norma ASTM A763-93) com o de reativação eletroquímica DL-EPR, e, observaram maior grau de sensitização na faixa de temperatura entre $500^{\circ} \mathrm{C}$ e $650^{\circ} \mathrm{C}$. Acima de $700^{\circ} \mathrm{C}$ notaram que o aço recuperou a resistência à corrosão intergranular. No entanto, para os aços P430 e AISI 430, na temperatura de $900^{\circ} \mathrm{C}$, em diferentes condições de resfriamento, notou-se o fenômeno de sensitização.

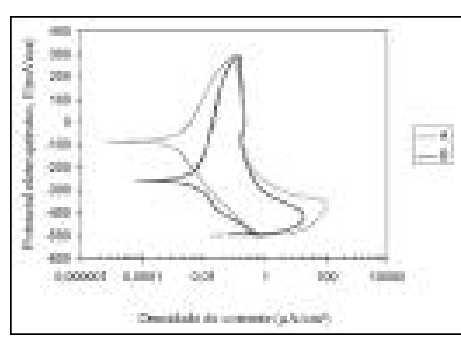

(a)

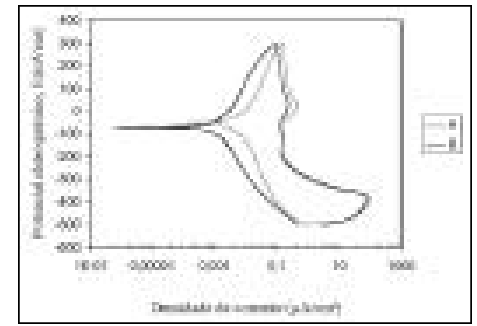

(b)
Figura 5. Curvas de polarização cíclica obtidas pelo método DL-EPR. Sistema: aço (a) AISI 444; (b) AISI 439 - 0,5 $\mathrm{M} \mathrm{H}_{2} \mathrm{SO}_{4}$; resfriamento ao forno após aquecimento a $950^{\circ} \mathrm{C}$ durante "A" 10 minutos e "B" 20 minutos. 


\section{CONCLUSÕES}

- Observou-se que o aço P430 apresentou maior grau de sensistização quando aquecido durante 10 minutos e resfriado ao forno, o que não foi observado para o tempo de 20 minutos, provavelmente em função da redifusão do cromo, devido a presença de $\mathrm{Ti}$ e $\mathrm{Nb}$, que, inibem a sensitização.

- O aço AISI 430 apresentou comportamento pior (com maiores valores no grau de sensitização), diferentemente do aço P430, que é estabilizado ao Ti.

- Os aços dos tipos AISI 444 e AISI 439 não apresentaram sensitização em nenhum dos meios de resfriamento.

- O grau de sensitização do aço P430 analisado variou em função do tempo e temperatura de tratamento térmico. $O$ ataque com ácido oxálico (Prática W - Norma ASTM A 763-93) e o método DLEPR mostraram variações principalmente no que diz respeito ao tipo de resfriamento.

- Para avaliar o grau de sensitização do material, o método DLEPR mostrou-se mais sensível que a Prática W. Os parâmetros utilizados neste método foram efetivos na identificação das regiões empobrecidas em cromo produzidas por precipitados em contornos de grão.

- No método DL-EPR foi observado, em alguns casos, um segundo máximo de densidade de corrente.

- O aço AISI 430 apresentou, em alguns resfriamentos, um intenso ataque generalizado quando submetido ao ensaio por imersão (Prática W).

- No geral, os valores do grau de sensitização dos aços AISI 430 e P430 diminuíram ou desapareceram com o aumento da velocidade de resfriamento das amostras durante os tratamentos térmicos.

\section{COMENTÁRIOS EXTRAS}

As Tabelas 2 (a) e (b) apresentam valores do grau de sensitização dos aços analisados empregando-se o método de reativação eletroquímica potenciocinética, versão duplo loop (DLEPR). Nota-se que o aço AISI 430, por não ser estabilizado ao Ti, apresenta um aumento do GS quando submetido a tempo maior (20 minutos) de tratamento térmico. O aço estabilizado ao $\mathrm{Ti}$, geralmente forma nitreto de titânio (TiN) em altas temperaturas, o que permite a redifusão do $\mathrm{Cr}$ em solução sólida, garantindo a inoxidabilidade do material, indicado pelo menor grau de sensitização do mesmo.

Esse comportamento, de redifusão do cromo, pode explicar o resultado que indica uma diminuição do GS para o aço P430 quando mantido em tempo maior (20 minutos).
$\mathrm{Na}$ avaliação do GS através do resfriamento em nitrogênio líquido foi possível constatar que o aço P430 e AISI 430 apresentaram suscetibilidade à sensitização, embora, em função da presença de uma atmosfera gasosa, o sistema empregado tenha propiciado condições heterogêneas de resfriamento.

A variação na velocidade de resfriamento das amostras durante tratamento térmico está relacionada com os resultados finais obtidos neste trabalho. No geral, à medida que a velocidade de resfriamento aumentou, reduziu-se o valor do grau de sensitização dos aços.

\section{CONSIDERAÇÕES FINAIS}

Em termos gerais, os aços AISI 444 e 439 mostraram-se mais resistentes à sensitização e consequentemente à corrosão intergranular. Os aços AISI 430 e AISI 430 modificado (P430) apresentaram maior sensibilidade à precipitação de carbonetos (ou nitretos) de cromo em seus contornos de grão, sendo que, o aço P430, mostrou-se, praticamente, melhor que o aço AISI 430, que não é estabilizado ao Ti.

Constatou-se que o meio de resfriamento de difícil manipulação, foi por nitrogênio líquido comercial, que necessita de uma técnica mais aprimorada de imersão e permanência no mesmo, sem que o meio externo interfira nos resultados finais, técnica esta, que ainda está sendo aprimorada.

A quantificação das estruturas resultantes do ataque, através de um programa com analisador de imagens, não foi possível devido à grande quantidade de figuras de corrosão sobre a amostra, a quantificação destas estruturas poderia ter um resultado "mascarado".

\section{Agradecimentos}

Os autores agradecem à ACESITA S.A.

\section{REFERÊNCIAS}

1 ASM INTERNATIONAL. Stainless steels. Materials Park, OH, 1994. 577p.

2 CHAWLA, S.L.; GUPTA, R.K. Materials selection for corrosion control. Materials Park, OH: ASM International, 1993. p. 24-27, 65-73, 128-131.

3 SEDRIKS, A. J. Corrosion of stainless steels: intergranular corrosion. 2. ed. New York: Wiley, 1996. 437p.

4 WOLYNEC, S. Técnicas eletroquímicas em corrosão. São Paulo: EDUSP, 2003. 165p. 
5 AMERICAN SOCIETY FOR TESTING MATERIALS (ASTM). A763-93: Standard practices for detecting susceptibility to intergranular attack in ferric stainless steels. Materials Park, OH, 1999.

6 GIRALDO, C. A. S.; MAGNABOSCO, R.; FALLEIROS, N.A. Avaliação da resistência à corrosão intergranular do aço UNS S43000 após tratamento térmico a $600^{\circ} \mathrm{C}$. In: CONGRESSO ANUAL DA ABM, 58., 2003. Rio de Janeiro. Anais... São Paulo: ABM, 2003. 1 CD-Rom. p. 373-382.

7 MAGRI, M. Métodos eletroquímicos para avaliação da sensitização no aço inoxidáveis martensítico AISI 410. 1995. 150 p. Dissertação (Mestrado em Engenharia Metalúrgica) - Escola Politécnica da Universidade de São Paulo, São Paulo, 1995.

8 PIRES, R. F.; FALLEIROS, N. A. Avaliação da corrosão intergranular de aço inoxidável ferrítico através de método de reativação eletroquímica. In: CONGRESSO ANUAL DA ABM - INTERNACIONAL, 59., 2004, São Paulo. Anais... São Paulo: ABM, 2004. 1 CD-Rom.

9 GIRALDO, C. A. S.; FALLEIROS, N.A. Efeito da temperatura na resistência à corrosão intergranular do aço inoxidável ferrítico UNS S43000. In: CONGRESSO ANUAL DAABM - INTERNACIONAL, 59., 2004, São Paulo. Anais... São Paulo: ABM, 2004. 1 CD-Rom. p. 445-454.

10 GIRALDO, C. A. S.; FALLEIROS, N.A. Avaliação da corrosão intergranular de aço inoxidável ferrítico através de método de reativação eletroquímica. In: CONGRESSO ANUAL DAABM - INTERNACIONAL, 59., 2004, São Paulo. Anais... São Paulo: ABM, 2004. 1 CD-Rom. p. 482-491.

11 LOPES, J. A. M. Avaliação de técnicas eletroquímicas para quantificação de graus de sensitização de um aço AISI 304. 2004. 77p. Dissertação (Mestrado do Programa de Pós-Graduação da REDEMAT) - Universidade Federal de Ouro Preto, Ouro Preto, 2004.

12 LOPES, J. A. M.; CÂNDIDO, L. C. Measurement of sensitized structures obtained by brief time thermal treatment in austenitic stainless steel. In: COBEM 2005 - 18th International Congress of Mechanical Engineering by ABCM, 18., 2005, Ouro Preto, MG. Proceedings... p.1-5.

13 AMERICAN SOCIETY FOR TESTING MATERIALS (ASTM). A262-1986: Standard practices for detecting susceptibility to intergranular attack in austenitic stainless steels. Materials Park, $\mathrm{OH}, 1986$.

14 GIRALDO, C. A. S.; FALLEIROS, N.A. Corrosão intergranular do aço inoxidável ferrítico UNS S43000: correlação entre ensaio de imersão e ensaio de reativação eletroquímica DL-EPR. In: CONGRESSO ANUALDAABM, 60., 2005, Belo Horizonte. Anais... São Paulo: ABM, 2005. 1 CD-Rom, p. 491-500.

Recebido em: 08/01/2007

Aceito em: 22/03/2007

Proveniente de: CONGRESSO ANUAL DAABM, 61., 2006, Rio de Janeiro. São Paulo: ABM, 2006. 